\title{
Amygdaloid lesions and social dominance in the hooded rat'
}

\author{
B. N. BUNNELL \\ UNIVERSITY OF FLORIDA
}

Lesions of the amygdala were made in hooded rats whose aggressiveness and social dominance rank had been determined in a seminatural environment. There was a significant reduction in the number of inter-animal interactions and in the percentage of bouts won. Social rank decreased in some animals, but was maintained by others. The effects of the lesions appeared to result from a raised threshold to social stimuli.

Rosvold, Mirsky, \& Pribram (1954) found that two of three monkeys subjected to lesions which involved extensive damage to the amygdaloid complex dropped from the top to the bottom of a dominance heirarchy. Fuller, Rosvold, \& Pribram (1957) showed that dogs which had previously won out in competition for bones began to lose following amygdaloid lesions. The present study was designed to extend the findings from monkeys and dogs to rodents.

Subjects

Twenty male hooded rats from the University of Florida colony, 114-127 days old, were divided into four groups of five animals each. Pelage marking was used to identify individual Ss.

Apparatus

The groups were housed in cages $3 \mathrm{ft}$. wide, $4 \mathrm{ft}$. deep, and $5 \mathrm{ft}$. high which were made from $1 / 2$ in. hardware cloth. The front wall was covered with fine window screening painted white to give one way observation. Each cage contained a feeder and an elevated wooden nest. A water bottle was attached to the outside of the front wall, with the metal straw protruding into the cage. A normal $12 \mathrm{hr}$. light-dark cycle was maintained, using $15 \mathrm{w}$ bulbs for illumination; another circuit, using $100 \mathrm{w}$ bulbs, served to signal the availability of water to the Ss.

Procedure

Ss were placed on a 23-hr. water deprivation schedule, with water availability coinciding with the observation periods. Observations were made between 3:00 and 4:00 p.m. daily. Each observation period was initiated by turning on the bright lights and attaching the water bottles to the cages. The Ss readily learned to emerge from the nest boxes in response to the light signal.

Three behavioral scores were recorded: (1) Frequency of interactions, with an interaction defined as an overt change in the behavior of an animal when it encountered another animal; (2) Number of wins and losses, defined as forcing an animal to flee, or fleeing from another animal, respectively; and (3) Aggressiveness, in which each interaction was rated on the
Klein-Hall (Hall \& Klein, 1942) aggressiveness scale, modified to include a negative score used when a $S$ fled from or submitted to an aggressor. (The order in which the animals drank was recorded but not used because it lacked stability both between and within the groups.) Social dominance rank was determined from the win-loss scores each $S$ made against every other animal in its group. An $S$ was said to be dominant over another if it won at least $75 \%$ of its encounters with that animal.

Four observers were trained in the scoring procedures during preliminary observations of the groups. Normally, each observer scored a different group during each observation period. Observer reliability remained high through the testing periods, as indicated by good agreement between group scores across observation periods.

After weighing and marking, the animals were placed in the testing cages and adapted to the water deprivation schedule for 2 weeks. After 12 observation periods, the social rank in three of the groups was sufficiently clear to permit the first set of operations. The social organization of the fourth group was not complete at this time and observations on these Ss were continued until the second series of operations were performed at which time they were also operated.

The groups were removed from the testing cages and housed individually with ad lib food and water 48 hr. prior to surgery and throughout the 14-day postoperative recovery period. Twenty-four hr. before the end of the recovery period the water deprivation schedule was resumed. The groups were then returned to the testing cages for eight postoperative observation periods. The procedure was repeated a second time, with the Ss in all four groups being isolated, given lesions, allowed 14 days to recover, and returned to the group' situation for postoperative testing. In all, seven $\mathrm{Ss}$ received lesions in the amygdaloid complex. Four of these had been dominant, one was intermediate in social rank and two had been submissive prior to surgery.

\section{Surgery and $\mathrm{Histology}$}

The bilateral amygdaloid lesions were made with a RF lesion generator under pentobarbital sodium anesthesia. Atropine sulphate was used as a premedication to reduce respiratory complications. The animals' diets were supplemented with condensed milk and wet mash until they resumed eating solid food. In each series of operations, one $S$ in each group was given the amygdaloid lesion while the other four were subjected to control operations. For the control 
operations, the electrode was only lowered $1.5-2.0 \mathrm{~mm}$ into the brain and no current was passed.

At the conclusion of testing the animals were sacrificed and standard histological procedures used for lesion reconstruction. Lesion placement was satisfactory, with the most severe and consistent damage having been done to the basolateral amygdaloid nuclei. ${ }^{2}$ Results and Discussion

1. The effect of the lesions on the social structure in the groups was to obscure the dominance-subordination relationships. The four Ss which had been dominant prior to amygdalectomy began to lose bouts to the other animals in their groups after surgery. However, two Ss, despite an increased frequency of losses, maintained apparent first rank. The other two top-ranked Ss won and lost about an equal number of times. One of these dropped one rank immediately after operation, but remained clearly dominant over two of its opponents until retested a month later ( after lesion was given to another member of its group) at which time it dropped into a tie for the lowest rank in the group.

The two animals which had been ranked fifth, and the one with intermediate ranking prior to surgery lost a greater percentage of bouts after amygdalectomy and showed no shift in social rank. All three continued to win occasionally.

2. Preoperatively, the experimental Ss won a total of 336 bouts and lost 143. Postoperatively, they won 180 and lost 191. The preoperative mean percentage of wins for the amygdaloid Ss was $67.86 \%$; postoperatively it was $50.01 \%$. The drop was statistically significant $(t=2.53, d f=6, p<.05$, two-tailed) .

3 . The mean aggressiveness-interaction (A/I) score of each animal was computed. For the controls the mean $\mathrm{A} / \mathrm{I}$ score was 1.20 during the initial testing phase, 1.12 after the first series of operations, and 1.16 for the observations made after the second series of operations. These scores were not significantly different from each other.

Six of the seven amygdalectomized animals showed a decrease in aggressiveness; the seventh increased after surgery. The preoperative mean A/I score was 1.34, postoperatively it was 1.04 . The decrease was not significant ( $t=1.67, \mathrm{df}=6, \mathrm{p}>.10$, two-tailed).

Qualitatively, the amygdalectomized animals appeared to have a higher threshold for aggression, but once aroused they were capable of fighting as aggressively as they had preoperatively.

4 . In order to examine the amount of social interaction in the groups, the mean number of interactions each $S$ made per opponent per observation period (I/O/O score) was computed. For controls, the mean I/O/O score was 3.84 during the initial testing phase, 3.33 after the first series of operations, and 2.99 after the second series. This decrease was not significant. Within each postoperative testing period, an approxi- mately equal number of Ss showed an increase as showed a decrease in interaction frequency. No systematic trends in the direction of individual changes could be found across observation periods for the animals. The general downward trend appeared to be a function of the decreased interaction frequency exhibited by the amygdaloid animals.

All seven amygdaloid Ss decreased substantially in $\mathrm{I} / \mathrm{O} / \mathrm{O}$ scores. (The range of the difference scores was from .96 to 2.94.) The drop from a preoperative mean of 4.61 to a postoperative mean of $2.92 \mathrm{I} / \mathrm{O} / \mathrm{O}$ was significant $(t=5.83, d f=6, p<.05$, two-tailed).

The results of the present study are in general agreement with those obtained from the studies of the effects of amygdalectomy on monkey (Rosvold et al, 1954) and dog (Fuller et al, 1957). The fact that the status changes were not as clear as those obtained in some monkeys may be due to the relatively low levels of aggression exhibited by all of the rats. One of the Rosvold et al monkeys did not drop in status when it was operated after two other dominant animals in the group had been made submissive by amygdalectomy. This was attributed to an altered social situation in which there was little aggression and very few challenges to the dominant animal after it received the operation.

Fuller et al reported that one of the amygdalectomized dogs was observed to fight fiercely many times. This animal was not the aggressor, but if challenged could fight as well or better than its control. Similarly, several of the rats in the present study appeared to be less responsive to attacks by other animals than before surgery, but could and did beat them when sufficiently aroused.

The decrease in percentage of interactions won and the trend (nonsignificant) toward lower aggression scores after amygdalectomy, together with the reduction in the number of social interactions are interpreted as being the result of a raised threshold to social stimuli.

\section{References}

Fuller, J. L., Rosvold, H. E., \& Pribaum, K. H. The effect on affective and cognitive behavior in the dog of lesions of the pyriform-amygdala-hippocampal complex. J. comp. physiol. Psychol., 1957, 50, 89-96.

Hall, C. S., \& Klein, S. J. Individual differences in aggressiveness in rats. J. comp. Psychol., 1942, 33, 371-383.

Rosvold, H. E., Mirsky, A. F., \& Pribaum, K. H. Influence of amygdalectomy on social behavior in monkeys. J. comp. physiol. Psychol., 1954, 47, 173-178.

\section{Notes}

1. Supported by Grant B1149 from the National Science Foundation. The assistance of Dr. W. Rea Knight, F. J. Sodetz, and Judi Barry in making the behavioral observations and of Dr. Knight and $\mathrm{K}$. $\mathrm{E}$. Achenbach in helping with the surgery is gratefully acknowledged. 2. Copies of the lesion reconstruction for the seven amygdaloid animals may be obtained by writing to the author. 